\author{
Military Technical College \\ Kobry El-Kobbah, \\ Cairo, Egypt
}

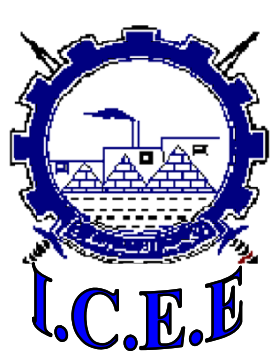

REM-1 $5^{\text {th }}$ International Conference

on

Chemical \& Environmental Engineering

25 - 27 May, 2010.

Recent Advances in Energetic Materials

\title{
ROLE OF POLYMERIC MATERIALS IN IMPROVEMENTS OF ENERGETIC MATERIALS CHARACTERISTICS
}

\section{ABSTRACT}

Mostafa K. Hadhoud*

Deut to new and changing applications, modern energetic materials and compositions have to fulfill sophisticated and even opposite features regarding to performance, sensitivity vulnerability and stability, ect. Energetic materials for military applications include secondary explosive, gun propellants, sold rocket propellants and pyrotechnic compositions. One of the ways to improve the above mentioned characteristics of the applied energetic materials is the application of polymeric materials as a basic component in its formulations. Since the end of WW II, the art was based on application of thermoplastic polymeric materials, followed by thermoset polymers and nowadays the work based on application of energetic polymeric materials. This paper is based on describing the history of application of polyme ric as a basic component in improved energetic compositions and describing the future and polymer role in improvement of mechanical, performance, sensitivity, stability and vulnerability of the based energetic materials and compositions.

\footnotetext{
${ }^{*}$ Egyptian Armed Forces
} 